\title{
Importance And Implementation Of Nursing Documentation: Review Study
}

\author{
Osama A Alkouri
}

King Abdulla University Hospital, Catheterization department, Irbid, Jordan

\section{Ahed J AlKhatib}

Department Of Legal Medicine, Toxicology of Forensic Science and

Toxicology, School of Medicine, Jordan University of Science and

Technology (JUST), Irbid , Jordan

Mariam Kawafhah

Irbid National University, Jordan

doi: 10.19044/esj.2016.v12n3p101 URL:http://dx.doi.org/10.19044/esj.2016.v12n3p101

\begin{abstract}
This study was conducted to review the literature about nursing documentation. We presented the importance and implementation of nursing documentation. The importance of this topic has been realized here, in Jordan, and the Ministry of Health has recently started application of electronic documentation systems. Nursing documentation can be either paper based or electronic based documentation. Paper based documentation has been described not meet the required standards. We argued the standards of nursing documentation that should be met including completeness, clearing, and concision.
\end{abstract}

Keywords: Nursing documentation, paper based documentation, electronic documentation

\section{Introduction}

Nursing documentation is considered as an important indicator to develop nursing care. According to patient safety law, nurses have to document nursing interventions (Öhlén, 2015). In Europe, it has been pointed to the attempts to standardize nursing records (Thoroddsen et al., 2009).

On the global level, the nature of nursing career involves that nurses carry out similar duties including the documentation of patients' care, assessments and finding and outcome of care (Hearthfield, 1996). In their study, Moody and Snyder (1995) showed that documentation took about 15$20 \%$ of the nurses' time. 
According to Irving et al (2006), nursing documentation can be viewed as the record of care planned and or care provided to patients. Nursing documentation was described by the College of Registered Nurses of British Columbia (CRNBC, 2007) as a generated information, written or electronic, that describes the care or service rendered to individual client or group of client. In fact it is an accurate account of what has occurred and when it occurred.

Two studies, Bakken (2007) and Hansebo et al (1999), expressed their views regarding nursing documentation to involve a description of nurses tasks, a method for problem solving and decision making as well as a theoretical or philosophical model of thinking and describing the care process.

\section{The reasons for nursing documentation}

It is thought that the importance of nursing documentation cannot be overemphasized. Furthermore, nursing documentation is considered as a way of communication, and presents as an indicator for quality of care (Ammenwerth et al., 2003). Nursing documentation is considered a crucial phase in the nature of nursing as a career with the purpose of determining the factors that help nursing process and others that form the bases of nursing decision-making (Karkkaninen and Eriksson, 2003).

It is worth to mention that the perception of nurses towards documentation implies nursing documentation as a significant step in their daily practice as well as emphasizing patients safety (Bjorvell et al., 2003). Nursing documentation offers various options to enable nurses making choices regarding decision making for optimal care ( Jefferies et al., 2010).

According to Cheevakasemsook et al (2006), nursing documentation has the following important aspects which include offering a legal evidence of the medical process and outcomes of care; providing an instrument or tool to assess the quality, efficiency and effectiveness of patient care; giving evidence for several issues such as research, financial and ethical qualityassurance purposes; providing the database infrastructure supporting development of nursing knowledge; and helping in creating benchmarks to develop nursing education and standards of clinical practice. It has been argued that optimal use of nursing documentation is likely to achieve if documentation is accurate (Ellingsen and Munkvold, 2007).

\section{Principles of documentation}

Appropriate nursing documentation has various principles including objectivity, specificity, clearing and consistency, comprehensive, respecting confidentiality, and recording errors (Chelagat et al., 2013). 


\section{Quality of nursing documentation}

Documentation is considered as a communication tool to exchange the information stored in records between nurses and other caregivers (Urquhart et al. 2009). It is believed that the quality of nursing documentation plays very important roles in encouraging structured, consistent and effective communication between caregivers and facilitates continuity and individuality of care and safety of patients (Bjo" rvell et al. 2000, Voutilainen et al.2004).

Nursing documentation has been defined as the record of nursing care that is planned and given to individual patients and clients by qualified nurses or by other caregivers under the direction of a qualified nurse (Urquhart et al. 2009). Nursing documentation is an attempt to present the issues that occurred in the nursing process and the information that leads to decision-making including admission, nursing diagnoses, interventions, and the evaluation of progress and outcome (Nilsson and Willman 2000, Karkkainen and Eriksson 2003).

Nursing documentation has other uses such as quality assurance, legal purposes, health planning, allocation of resources and nursing development and research, and accordingly nursing documentation has to have valid and reliable information and to be compatible with working standards (Idvall and Ehrenberg 2002, Karkkainen and Eriksson 2003, Urquhart et al. 2009).

The history of nursing documentation has started since the early days of Nightingale (Gogler et al. 2008). It is worth to mention that nursing documentation was improved with the introduction of the nursing process into the clinical setting (Oroviogoicoechea et al. 2008). The nursing process is regarded as a scientific approach in which critical thinking is used to solve problems and this approach was introduced into nursing practice and education Yura and Walsh in 1967 (Wang et al., 2011).

Nursing records are usually of low quality (Wan et al., 2011). Several studies showed that nursing documentation records were insufficient regarding the nursing care provided to a patient (Ehrenberg and Birgersson, 2003; Voutilainen et al., 2004; Irving et al., 2006; Mahler et al., 2007; Oroviogoicoechea, Elliott, and Watson, 2008). It was also indicated that data was not concisely and clearly presented (Whyte, 2005).

It has been recognized that the traditional paper based documentation does not cope with modern health requirements, and this may due to the nature of manual documentation process in which documentation is often repetitive and manipulation of data is not an easy process (Cheevakasemsook et al., 2006; Yu et al., 2008). Other studies pointed to withdraw backs of paper-based records in which documentation is illegible, lacking information about individualized patient care, containing useless information and missing 
the signatures of care staff (Ammenwerth et al., 2001; Whyte, 2005; Urquhart et al., 2009).

The use of information technology has witnessed wide use by health care organizations to support care delivery because electronic documentation systems help in data capturing through the use of structured date entry and formalized nursing language (Ehrenberg and Ehnfors, 2001). Electronic documentation systems have the advantages in offering health professionals with increased access to more complete, clear, accurate, legible and up-todate patient information (Helleso and Ruland, 2001; Oroviogoicoechea, Elliott, and Watson, 2008).

\section{Conclusion}

Nursing documentation is very crucial in health care settings and reflects various aspects including the awareness level of nurses in their roles in providing health services in a good quality. Nursing documentation have two main forms: paper based documentation and electronic based documentation. Paper based documentation has certain drawbacks such as lacking the comprehensiveness and clarity. Accordingly, a strong trend to shift paper based documentation towards electronic documentation has been witnessed.

\section{References:}

Agneta Öhlén (2015). ADVANCED HOME CARE NURSES' EVERYDAY PRACTICE. PhD thesis, Karolinska Institute, Stockholm, Sweden.

Ammenwerth E, Eichstadter R, Haux R, Pohl U, Rebel S, Ziegler S. A (2001). Randomized Evaluation of a Computer-Based Nursing Documentation System. Methods inf. med., 40: 61-68.

Ammenwerth, E., Mansmann, M., Iller, C., Eichstädter, R. (2003). Factors affecting and affected by user acceptance of computer-based nursing documentation: results of a two-year study. Journal of the American Medical Informatics Association, 10(1), 69-84.

Bakken, S. (2007). Building standard-based nursing information systems. Washington, DC: Pan American Health Organization.

Bjo“ rvell C., Thorell-Ekstrand I and Wredling R (2000). Development of an audit instrument for nursing care plans in the patient record. Quality in Health Care 9, 6-13.

Bjorvell, C., Thorell-Ekstrand, I., Wredling, R. (2003). Prerequisites and consequences of patient records as perceived by a group of registered nurses. Journal Of Clinical Nursing, 12, 206-214.

Cheevakasemsook A, Chapman Y, Francis K, Davis C (2006). The study of nursing documentation complexities, Int J Nurs Pract., 12:366 -374.

CRNBC (2007). Nursing Documentation. Crnbc, 151, 1-24. 
Dinah Chelagat, Tecla Sum, Millicent obel, Alex Chebor, Robert Kiptoo, Priscah Bundotich-Mosol (2013). Documentation: Historical Perspectives, Purposes, Benefits and Challenges as Faced by Nurses. International Journal of Humanities and Social Science, 3 (16): 236-240.

Ehrenberg A, Birgersson C (2003). Nursing documentation of leg ulcers: adherence to clinical guidelines in a Swedish primary health care district. Scand J Caring Sci., 17: 278-284.

Ehrenberg A, Ehnfors M (2001). The accuracy of patient records in Swedish nursing homes: congruence of record content and nurses' and patients' descriptions. Scand J Caring Sci., 15: 303-310.

Ellingsen, G., Munkvold, G. (2007). Infrastructural arrangements for integrated care: implementing an electronic nursing plan in a psychogeriatic ward. International Journal of Integrated Care, 7, 1-11.

Gogler J., Hullin C., Monaghan V. Searle C (2008). The chaos in primary nursing data: good information reduces risk. HIC 2008 Australia's Health Informatics Conference ISBN 9780980552003.

Hansebo, G., Kihlgren, M., Ljunggren, G. (1999). Review of nursing documentation in nursing home wards-changes after intervention for individualized care. Journal of Advanced Nursing, 29, 1462-1473.

Hearthfield M (1996). Nursing documentation and nursing practice: a discourse analysis. Journal of Advanced Nursing, 24, 98-103.

Helleso R, Ruland CM (2001). Developing a module for nursing documentation integrated in the electronic patient record. J Clin Nurs, 10: 799-805.

Idvall E. and Ehrenberg A. (2002). Nursing documentation of postoperative pain management. Journal of Clinical Nursing 11, 734-742.

Irving K, Treacy M, Scott A, Hyde A, Butler M, MacNeela P (2006). Discursive practices in the documentation of patient assessments. J Adv Nurs, 53: 151-159.

Jefferies, D., Johnson, M., Griffiths, R. (2010). A meta-study of the essentials of quality nursing documentation. International Journal of Nursing Practice, 16(2), 112-124.

Karkkainen O. and Eriksson K. (2003). Evaluation of patient records as part of developing a nursing care classification. Journal of Clinical Nursing 12, 198-205.

Mahler C, Ammenwerth E, Wagner A, Tautz A, Happek T, Hoppe B, Eichstadter R (2007). Effects of a computer-based nursing documentation system on the quality of nursing documentation. J Med Syst, 31: 274-282.

Moody, L., Snyder, P. (1995). Hospital provider satisfaction with a new documentation system. Nursing Economics, 13, 24-31.

Nilsson U.B. and Willman A (2000). Evaluation of nursing documentation. Scandinavian Journal of Caring Sciences 14(3), 199-206. 
Ning Wan, Ping Yu, David Hailey, Deborah Oxlade (2011). Developing Measurements of Quality of Electronic versus Paper-based Nursing Documentation in Australian Aged Care Homes. electronic Journal of Health Informatics, 6(1): 1-6.

Ning Wang, David Hailey, Ping Yu (2011). Quality of nursing documentation and approaches to its evaluation: a mixed-method systematic review. Journal of Advanced Nursing 00(0), 000-000. doi: 10.1111/j.13652648.2011.05634.x

Oroviogoicoechea C, Elliott B, Watson S (2008). Review: evaluating information systems in nursing. J Clin Nurs, 17: 567-575.

Thoroddsen A, Saranto K, Ehrenberg A, Sermeus W. (2009) Models, Standards and Structures of Nursing Documentation in European Countries. Study of health care technology information;146:327-331.

Urquhart C, Currell R, Grant MJ, Hardiker NR (2009). Nursing record systems: effects on nursing practice and healthcare outcomes. Cochrane Database of Syst Revi. Issue 1.

Voutilainen P, Isola A, Muurinen S (2004). Nursing documentation in nursing homes - state-of-the-art and implications for quality improvement. Sand J Caring Sci., 18: 72-81.

Whyte M (2005). Computerised versus handwritten records. Paediatric Nursing, 17:15-18.

Yu P, Hailey D, Li H (2008). Caregivers' acceptance of electronic documentation in nursing homes, Journal of Telemedicine and Telecare., 14: 261-65. 